\title{
PREVALENCE OF CONVENTIONAL CARDIOVASCULAR RISK FACTORS IN PATIENTS WITH ACUTE CORONARY SYNDROMES IN SLOVAKIA
}

\author{
Roman Alberty ${ }^{1}$, Martin Studenčan ${ }^{2}$, František Kovári ${ }^{3}$ \\ ${ }^{1}$ Department of Biology and Ecology, Faculty of Natural Sciences, Matej Bel University, Banská Bystrica, Slovakia \\ ${ }^{2}$ Cardiocentre of Faculty Hospital J. A. Rayman, Prešov, Slovakia \\ ${ }^{3}$ Cardiocentre of Martin Faculty Hospital, Martin, Slovakia
}

\section{SUMMARY}

Background: Acute coronary syndrome (ACS) is a major health problem and the leading cause of death and disability in Slovakia. This is the first study to describe the prevalence rate of conventional cardiovascular risk factors in patients hospitalized for ACS.

Methods: Hypertension, diabetes mellitus, hyperlipidemia and cigarette smoking were documented in 1,567 cases (mean age, SD: $66.1 \pm 12.0$ years, 34.8\% of females) enrolled in the SLOVAKS registry from August 2011 through September 2011.

Results: Overall, $83.5 \%$ (95\% Cl, 81.6-85.2\%) of the patients with ACS had hypertension, $65.0 \%$ (62.5-67.2\%) had a hyperlipidemic profile, $32.6 \%$ (30.3-34.9\%) were diagnosed with diabetes, and 27.6\% (25.1-29.8\%) were smokers at the time of a heart-related event. Only $5 \%$ of patients with ACS lacked any of the 4 conventional risk factors. Higher prevalence rates of all major risk factors, except smoking, were detected in women than in men, in older ( $\geq 65$ years of age) than younger patients, and in rural $(<2,000$ inhabitants) than in urban areas. Premature ACS ( $<45$ years of age) was associated with smoking in men, and smoking and hypertension in women. Smoking, in all risk factor combinations, reduced the age at the time of a heart-related event, on average, by 10.0 years in men and by 12.4 years in women.

Conclusions: The results of this study suggest an appreciable burden of major cardiovascular risk factors and also highlight differences that may aid the targeting of public health interventions.

Key words: acute coronary syndrome, risk factors, epidemiology, case-retrospective study

Address for correspondence: R. Alberty, Department of Biology and Ecology, Faculty of Natural Sciences, Matej Bel University, Tajovského 40, SK-97401 Banská Bystrica, Slovakia. E-mail: roman.alberty@umb.sk

https://doi.org/10.21101/cejph.a4351

\section{INTRODUCTION}

Acute coronary syndrome (ACS) is a major health problem and the leading cause of death and disability in men and women in Slovakia (1). In comparison with neighbouring countries the recent mortality rate from cardiovascular disease in Slovakia was the same as in Hungary, but 1.5 times higher than in Poland and the Czech Republic, and 2.5 times higher than in Austria (2).

In 2012, 75,454 individuals, i.e. $2 \%$ of the adult Slovak population (aged $\geq 25$ years), were hospitalized as suffering from a cardiovascular system disease: $21 \%$ of them had ACS, $26 \%$ stroke, 22\% hypertensive disease, and 31\% peripheral vascular disease. Among cardiovascular patients, ACS is considered the most serious life-threatening disease (1).

Extensive epidemiological research has identified hypertension, diabetes mellitus, hyperlipidemia, and cigarette smoking as conventional risk factors for cardiovascular diseases (3). In the last 25 years, during the time of transformation from socialism to a free market economy, two epidemiological studies conducted to monitor cardiovascular mortality and its major risk factors were performed in Central Europe $(4,5)$.
Both the Countrywide Integrated Noncommunicable Disease Intervention (CINDI) Programme in Slovakia and the extensive multi-centre international WHO MONICA Project in the Czech Republic suggested a weak upward trend in the cardiovascular death rate and a higher prevalence of known risk factors such as obesity (15-26\%), hyperlipidemia (66-74\%), cigarette smoking (17-31\%), and hypertension (27-37\%) in the general population aged $25-64$ or 35-64 years compared to western, high-income European countries $(4,5)$.

In order to collect precise information on demographic characteristics, in-hospital courses, treatment strategy, and incidence of major cardiovascular risk factors from all causes of ACS in our country, a National registry (SLOVAKS registry) of patients who had ACS and were admitted to hospital or coronary care units was created in 2007. A total of 69 hospitals have participated in this project at the time of this study; it constitutes $85 \%$ of all clinical treatment services for ACS in Slovakia. The details of the SLOVAKS registry of ACS have been previously described (6).

The role of conventional risk factors for increased cardiovascular events in the general population is indisputable. However, it is often hypothesized that more than $50 \%$ of patients with 
coronary heart diseases lack any of the conventional risk factors (7). Therefore, the current study was undertaken to determine the prevalence rate of the 4 conventional risk factors (i.e. hypertension, diabetes, hyperlipidemia, and smoking) in patients with ACS hospitalized in various regions in Slovakia.

\section{MATERIAL AND METHODS}

We analyzed data of 1,567 consecutive patients with a definitively confirmed diagnosis of ACS - 1,022 men: mean age (SD) 63.4 (11.5) years and 545 women: mean age (SD) 71.1 (11.1) years included into the SLOVAKS registry in the time period from August 1, 2011 to September 30, 2011. ACS encompasses three distinct clinical conditions: ST-elevation myocardial infarction (STEMI), non-ST-elevation myocardial infarction (NSTEMI), and unstable angina (UA). Criteria for diagnosing both myocardial infarction and unstable angina were taken from guideline recommendations (8-10). No other specific inclusion or exclusion criteria were applied to registered patients. Information regarding diabetes, hypertension, hyperlipidemia, and cigarette smoking were collected during hospitalization.

The study was approved by the Ethics Committee of the Slovak Society of Cardiology and was performed in accordance with the Declaration of Helsinki (2008) of the World Medical Association. Before collection of any information, patients gave their informed consent to participate in the study.

Patients were defined as having diabetes if they had a history of diabetes or had been prescribed oral hypoglycemic drugs or insulin. Similarly, patients were defined as having hypertension or hyperlipidemia if they had a history of hypertension or hyperlipidemia or had been prescribed anti-hypertensive or lipidlowering therapy, respectively. Current smokers were defined as patients who continued to smoke ( $>1$ cigarette per day) at the time of the ACS event, or who had stopped smoking within the previous 30 days.

The scheme of this study follows that of the study of Khot et al. (11). In brief, the prevalence rates (95\% confidence interval, CI) for each cardiovascular risk factor per age group $(<45$, $45-54,55-64,65-74$, and $\geq 75$ years old), entry trial, and place of residence were computed for men and women. Two-months residence-specific and adjusted incidence of ACS per 100,000 persons older than 25 were also computed. Furthermore, we investigated the relationship between a number of conventional risk factors and the patient's age at the time of a heart-related event, and the relationship between every risk factor combination and the patient's age at the time of a heart-related event and the patient's smoking status.

An urban area was defined as a commune with more than 2,000 inhabitants; other areas were defined as rural. Urban areas were further stratified according to the number of inhabitants, with the following thresholds: 5,000, 50,000, 100,000 and 500,000 inhabitants. The rural/urban status of the place of residence was based on the 2011 census (12).

Statistical analyses were calculated with PASW software 17.0 (SPSS Inc., Chicago, IL, USA). Differences between study groups were assessed by Fisher's exact test for categorical variables, and the $t$ test for continuous variables. The trend for the association between categorical risk factors and age, and the size of residence was tested with the Cochran-Armitage trend test (XLSTAT, Microsoft Corp., Redmond, WA, USA). All tests were two-tailed and $\mathrm{p}<0.05$ was considered significant.

\section{RESULTS}

A total of 1,567 patients with ACS were included in the final analysis. Table 1 shows the trial entry categories of ACS and prevalence rate of conventional risk factors in women and men. Myocardial infarction was the discharge diagnosis for 1,002 (63.9\%) individuals, of whom there were 484 with STEMI and 518 with NSTEMI. The remaining patients were diagnosed as having UA (565, 36.1\%). Overall, the majority of patients with STEMI (70.0\%), NSTEMI (64.3\%) and UA (61.9\%) were males. Women with ACS were significantly older than men at hospital admission: mean age 71.1 vs. 63.4 years (SD, 11.3 vs. 11.5 years), respectively $(\mathrm{p}<0.001)$. Of the whole group of patients, $83.5 \%$ (95\% CI 81.6-85.3\%) had hypertension, 65\% (62.5-67.2\%) had hyperlipidemia, $32.6 \%(30.3-34.9 \%)$ had diabetes, and $27.6 \%$ (25.1-29.8\%) of patients were smokers. Of men and women with ACS, 93.8\% (92.2-95.2\%) and 95.0\% (92.8-96.7\%), respectively, had at least 1 of the 4 conventional risk factors. For all risk factors except for cigarette smoking, the prevalence was significantly higher in women than in men $(\mathrm{p}<0.05$ or $\mathrm{p}<0.001)$.

Table 2 presents the prevalence of risk factors in the study population further stratified by age and gender. Women aged 55 years and older had a significantly higher prevalence of diabetes than similarly aged men $(\mathrm{p}<0.01$ or $\mathrm{p}<0.001)$, whereas current cigarette smoking was more common in men $(\mathrm{p}<0.01$ or $\mathrm{p}<0.001$ ). Similarly, the proportion of hypertension and hyperlipidemia was significantly higher in women over 55 than in

Table 1. Prevalence of conventional risk factors in patients with acute coronary syndrome by gender

\begin{tabular}{|l|c|c|}
\hline ACS, age and risk factors & $\begin{array}{c}\text { Women } \\
(\mathrm{N}=545)\end{array}$ & $\begin{array}{c}\text { Men } \\
(\mathrm{N}=1022)\end{array}$ \\
\hline ST-elavation MI, N & 145 & 339 \\
\hline Non-ST-elevation MI, N & 185 & 333 \\
\hline Unstable angina, N & 215 & 350 \\
\hline Age, mean (SD), years & $71.1(11.3)$ & $63.4(11.5)^{+++}$ \\
\hline Hypertension, N (\%) & $488(89.5)$ & $821(80.3)^{\star \star \star}$ \\
\hline Diabetes, N (\%) & $239(43.9)$ & $272(26.6)^{\star \star \star}$ \\
\hline Hyperlipdemia, N (\%) & $374(68.6)$ & $644(63.0)^{\star}$ \\
\hline Current smoking, N (\%) & $79(14.5)$ & $353(34.5)^{\star \star \star}$ \\
\hline Number of risk factors (\%) & & \\
\hline 0 & $27(5.0)$ & $63(6.2)$ \\
\hline 1 & $93(17.1)$ & $228(22.3)^{\star}$ \\
\hline 2 & $208(38.2)$ & $391(38.3)$ \\
\hline 3 & $201(36.9)$ & $283(27.7)^{\star \star \star}$ \\
\hline 4 & $16(2.9)$ & $57(5.6)^{\star}$ \\
\hline
\end{tabular}

Values are expressed as numbers $(\mathrm{N})$ and percentages unless otherwise specified. t-test for unpaired data significant at: ${ }^{++} p<0.001$

Comparing risk factor prevalence between women and men at: ${ }^{*} p<0.05$ and ${ }^{* * *} p<0.001$.

$\mathrm{MI}$ - myocardial infarction 
Table 2. Prevalence of conventional risk factors in patients with acute coronary syndrome by age and gender

\begin{tabular}{|c|c|c|c|c|c|c|c|c|c|c|}
\hline & \multicolumn{10}{|c|}{ Age, years } \\
\hline & \multicolumn{2}{|c|}{$<45$} & \multicolumn{2}{|c|}{$45-54$} & \multicolumn{2}{|c|}{$55-64$} & \multicolumn{2}{|c|}{$65-74$} & \multicolumn{2}{|c|}{$\geq 75$} \\
\hline & Women & Men & Women & Men & Women & Men & Women & Men & Women & Men \\
\hline & \multicolumn{10}{|c|}{ Individual risk factors } \\
\hline $\mathrm{N}$ & 12 & 49 & 40 & 174 & 91 & 333 & 161 & 265 & 241 & 201 \\
\hline Hypertension & 83.3 & 55.1 & 62.5 & $87.2^{\star \star *}$ & 87.9 & 82.9 & 92.5 & $86.0^{*}$ & $92.9^{+++}$ & $86.1^{\star++}$ \\
\hline Diabetes & 33.3 & 14.3 & 20.0 & 13.8 & 46.2 & $30.0^{\star *}$ & 44.1 & $31.3^{\star *}$ & 47.3 & $28.9^{\star \star \star+++}$ \\
\hline Hyperlipidemia & 41.7 & 44.9 & 52.5 & 60.3 & 63.7 & 66.4 & 77.6 & $65.3^{* *}$ & 68.5 & 61.2 \\
\hline \multirow[t]{2}{*}{ Smoking } & 58.3 & 71.4 & 52.5 & 54.0 & 24.2 & $40.8^{\star \star}$ & 11.8 & $23.0^{* *}$ & $4.1^{+++}$ & $13.4^{\star \star \star+++}$ \\
\hline & \multicolumn{10}{|c|}{ Number of risk factors } \\
\hline 0 & 8.3 & 8.2 & 10.0 & 6.9 & 6.6 & 4.8 & 3.1 & 6.8 & 4.6 & 6.5 \\
\hline 1 & 25.0 & 32.7 & 27.5 & $25.3^{*}$ & 16.5 & 19.2 & 13.0 & $20.8^{*}$ & 17.8 & $24.4^{+++}$ \\
\hline 2 & 25.0 & 32.7 & 37.5 & 38.5 & 30.8 & $36.3^{\star \star \star}$ & 42.2 & 37.7 & 39.0 & 43.3 \\
\hline 3 & 33.3 & 18.4 & 20.0 & 23.6 & 40.7 & 30.9 & 38.5 & 30.2 & 37.3 & $24.9^{\star \star}$ \\
\hline 4 & 8.3 & 8.2 & 5.0 & 5.7 & 5.5 & 8.7 & 3.1 & 4.5 & $1.2^{+}$ & $1.0^{++}$ \\
\hline
\end{tabular}

All prevalence data are expressed as percentages.

Comparing risk factor prevalence between women and men within the same age group at: ${ }^{*} p<0.05,{ }^{* *} p<0.01$, and ${ }^{* * *} p<0.001$.

Test for linear trend between risk factor prevalence and age at: ${ }^{+} p<0.05,{ }^{++} p<0.01$, and ${ }^{+++} p<0.001$ (the data take the form of a $2 \times 5$ contingency table, separately for men and women).

Table 3. Prevalence of conventional risk factors in patients with acute coronary syndrome according to trial entry criteria

\begin{tabular}{|c|c|c|c|c|c|c|c|c|c|c|}
\hline \multirow[b]{3}{*}{ Entry criteria } & \multicolumn{10}{|c|}{ Age, years } \\
\hline & \multicolumn{2}{|c|}{$<45$} & \multicolumn{2}{|c|}{$45-54$} & \multicolumn{2}{|c|}{$55-64$} & \multicolumn{2}{|c|}{$65-74$} & \multicolumn{2}{|c|}{$\geq 75$} \\
\hline & Women & Men & Women & Men & Women & Men & Women & Men & Women & Men \\
\hline & \multicolumn{10}{|c|}{ ST-elevation myocardial infarction } \\
\hline $\mathrm{N}$ & 5 & 29 & 15 & 65 & 27 & 112 & 31 & 89 & 67 & 44 \\
\hline Hypertension & 100.0 & $44.8^{\star}$ & 46.7 & 53.8 & 66.7 & 63.4 & 87.1 & 75.3 & $85.1^{+}$ & $65.9^{\star++}$ \\
\hline Diabetes & 40.0 & 17.2 & 13.3 & 12.3 & 37.0 & 19.6 & 29.0 & 21.3 & 31.3 & 18.2 \\
\hline Hypelipidemia & 40.0 & 41.4 & 40.0 & 40.0 & 33.3 & 48.2 & 51.6 & 43.8 & 50.7 & 43.2 \\
\hline Smoking & 60.0 & 75.9 & 66.7 & 60.0 & 33.3 & 48.2 & 19.4 & 33.7 & $4.5 \$$ & 13.6 \\
\hline \multirow[t]{2}{*}{ Zero RFs } & 0.0 & 10.3 & 20.0 & 13.8 & 18.5 & 12.5 & 9.7 & 13.5 & 10.4 & 20.5 \\
\hline & \multicolumn{10}{|c|}{ Non-ST-elevation myocardial infarction } \\
\hline $\mathrm{N}$ & 1 & 7 & 10 & 57 & 38 & 113 & 70 & 88 & 66 & 68 \\
\hline Hypertension & 0.0 & 100.0 & 90.0 & 80.7 & 94.7 & 93.8 & 94.3 & 93.2 & 97.0 & 94.1 \\
\hline Diabetes & 0.0 & 0.0 & 20.0 & 17.5 & 52.6 & $27.4^{\star \star}$ & 41.4 & 29.5 & 51.5 & $32.4^{\star+}$ \\
\hline Hypelipidemia & 0.0 & 57.1 & 80.0 & 78.9 & 84.2 & 81.4 & 78.6 & 77.3 & 89.4 & $60.3^{\star \star \star+}$ \\
\hline Smoking & 100.0 & 57.1 & 30.0 & 43.9 & 13.2 & $30.1^{*}$ & 10.0 & 13.6 & 7.6 & $17.6^{+++}$ \\
\hline \multirow[t]{2}{*}{ Zero RFs } & 0.0 & 0.0 & 0.0 & 1.8 & 2.6 & 0.9 & 1.4 & 2.3 & 0.0 & 2.9 \\
\hline & \multicolumn{10}{|c|}{ Unstable angina } \\
\hline N & 6 & 13 & 15 & 52 & 26 & 108 & 60 & 88 & 108 & 89 \\
\hline Hypertension & 83.3 & 53.8 & 60.0 & 69.2 & 100.0 & 91.7 & 93.3 & 89.8 & $95.4^{++}$ & $89.9^{+++}$ \\
\hline Diabetes & 33.3 & 15.4 & 26.7 & 11.5 & 46.2 & 43.5 & 55.0 & $43.2^{\star \star}$ & $54.6^{+}$ & $31.5^{\star \star \star}$ \\
\hline Hypelipidemia & 50.0 & 46.2 & 46.7 & 65.4 & 65.4 & 69.4 & 90.0 & $75.0^{*}$ & 66.7 & 70.8 \\
\hline Smoking & 50.0 & 69.2 & 53.3 & 57.7 & 30.8 & 44.4 & 10.0 & 21.6 & $1.9^{+++}$ & $10.1^{* \star+++}$ \\
\hline Zero RFs & 16.7 & 7.7 & 6.7 & 3.8 & 0.0 & 0.9 & 1.7 & 4.5 & 3.7 & 2.2 \\
\hline
\end{tabular}

All prevalence data are expressed as percentages.

Comparing risk factor prevalence between women and men within the same age group at ${ }^{*} p<0.05,{ }^{* *} p<0.01$, and ${ }^{* * *} p<0.001$.

Test for linear trend between risk factor prevalence and age at: ${ }^{+} p<0.05,{ }^{++} p<0.01$, and ${ }^{+++} p<0.001$ (the data take the form of a $2 \times 5$ contingency table, separately for men and women).

$\mathrm{RF}$ - risk factor 
Table 4. Prevalence of conventional risk factors in patients with acute coronary syndrome according to size of residence

\begin{tabular}{|c|c|c|c|c|c|}
\hline \multirow[b]{2}{*}{ Rural/urban area } & \multicolumn{5}{|c|}{ Size of residence ( $\mathrm{N}$ of citizens) } \\
\hline & 2,000 & 5,000 & 50,000 & 100,000 & 500,000 \\
\hline $\mathrm{N}$ of ACS patients & 517 & 215 & 522 & 178 & 135 \\
\hline Age, mean (SD) years & $66.7(12.1)$ & $66.2(10.9)$ & $65.4(11.7)$ & $66.8(11.9)$ & $64.5(13.9)$ \\
\hline $\mathrm{M} / \mathrm{F}$ ratio & 1.6 & 1.9 & 2.2 & 2.1 & 1.6 \\
\hline \multirow[t]{2}{*}{ ACS $/ 100,000^{\#}$} & 165.9 & 57.4 & 47.5 & 42.6 & 27.5 \\
\hline & \multicolumn{5}{|c|}{ Prevalence of risk factors } \\
\hline Hypertension & 88.0 & 82.3 & 82.8 & 77.0 & $80.0 * \star *$ \\
\hline Diabetes & 33.8 & 35.8 & 30.5 & 30.3 & 34.1 \\
\hline Hypelipidemia & 69.6 & 67.9 & 64.6 & 60.7 & $49.6^{\star \star *}$ \\
\hline \multirow[t]{2}{*}{ Smoking } & 23.4 & 30.2 & 28.7 & 27.0 & $35.6^{\star}$ \\
\hline & \multicolumn{5}{|c|}{ Number of risk factors } \\
\hline 0 & 4.8 & 6.6 & 5.7 & 5.6 & $8.1^{\text {** }}$ \\
\hline 1 & 16.6 & 19.5 & 20.7 & 29.8 & 23.7 \\
\hline 2 & 41.8 & 31.6 & 40.4 & 31.5 & 35.6 \\
\hline 3 & 32.9 & 36.3 & 28.4 & 29.7 & 25.9 \\
\hline 4 & 3.9 & 6.0 & 4.8 & 3.4 & 6.7 \\
\hline
\end{tabular}

Values are expressed as percentages unless otherwise specified.

"Two-month based acute coronary syndrome prevalence estimated for subjects $\geq 25$ years of age.

Test for linear trend between risk factor prevalence and size of residence at: ${ }^{*} p<0.05$, ${ }^{* *} p<0.01$, and ${ }^{* * *} p<0.001$ (the data take the form of a $2 \times 5$ contingency table in the same risk category).

ACS - acute coronary syndrome

age-matched men $(\mathrm{p}<0.01$ or $\mathrm{p}<0.001)$. Compared with young patients, older patients (persons older than 65) had the lowest prevalence of cigarette smoking but the highest rate of hypertension, diabetes and hyperlipidemia.

Of men and women with premature ACS (before the age of 45), $\sim 92 \%$ had at least one risk factor. Two risk factors were present in $32.7 \%$ of men and $25.0 \%$ of women, and three risk factors were present in $18.4 \%$ of men and $33.3 \%$ of women.

Table 3 shows the prevalence of conventional risk factors according to ACS classification. Fewer patients with NSTEMI and UA lacked any of the 4 conventional risk factors than those with STEMI. However, only in the cases of women with STEMI aged 45-54 and men with STEMI older than 75 did the number of patients lacking any of the 4 conventional risk factors exceed 20\%. Overall, patients admitted for STEMI had higher rates in their smoking habits, but lower rates of hypertension, diabetes and hyperlipidemia than other age-related patient groups. Regardless of trial entry criteria, the prevalence of diabetes was generally higher in women than in similarly aged men.

Table 4 presents the incidence of ACS and the prevalence of the conventional risk factors according to the size of patients' residence. During the period of the study, patients living in rural areas had a 3- to 6-fold higher incidence of ACS than those in urban areas (the total residence-adjusted incidence of ACS was 58.4 per 100,000 persons). In trend analysis, hypertension and hyperlipidemia was more prevalent among patients living in rural and small urban areas than among patients living in the largest cities in Slovakia $(\mathrm{p}<0.001)$, whereas current smoking was more common among patients living in large cities $(\mathrm{p}<0.05)$. In this context, patients with ACS living in urban areas had higher proportion of men and women without any of the 4 conventional risk factors for the disease $(\mathrm{p}<0.01)$.
The relationship between the number of conventional risk factors and age at the time of an ACS event is more or less controversial (Fig. 1). Among women and men, however, the patients without any of the 4 conventional risk factors were older on average by 3 years at the time of an ACS event than those showing all conventional risk factors. Strikingly, from this point of view, only current smoking was a relevant risk factor, reducing the mean age at the time of a heart-related event by 10 years in men and by 12.4 years in women, regardless of the risk factor combination (Fig. 2).

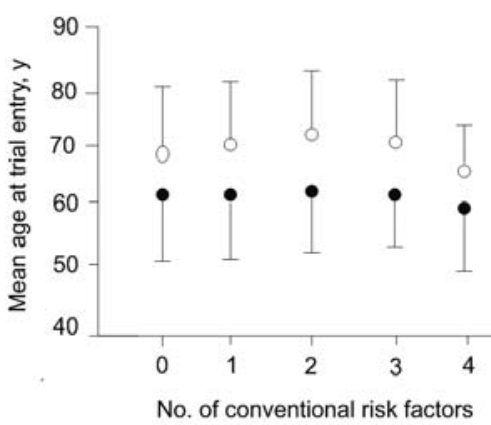

Fig. 1. Relationship between number of conventional risk factors and age at heart event.

In both sexes, only an increasing prevalence of 4 conventional risk factors significantly reduces the mean age at heart event ( $p<0.05$ for $2 v s .4$ risk factors). The error bars represent the standard deviations. 


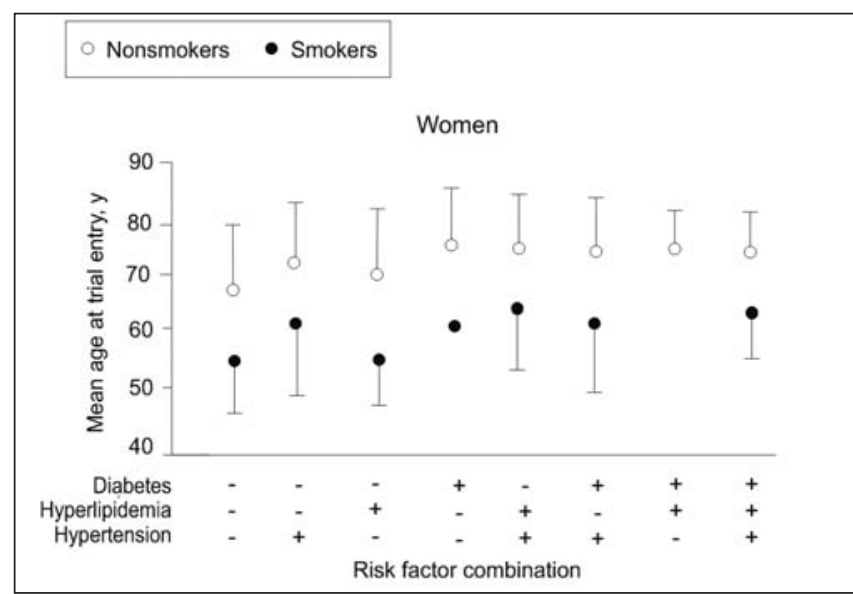

Fig. 2a. Relationship between conventional risk factor combinations and age at heart event stratified by smoking status in women.

For every risk factor combinantion, smoking reduces the age at heart event on average by 10.0 years in men and 12.4 years in women $(p<0.001$ for all smokers vs. non-smokers, except of +-- and ++- in both sexes because of small sample size). The error bars represent the standard deviations.

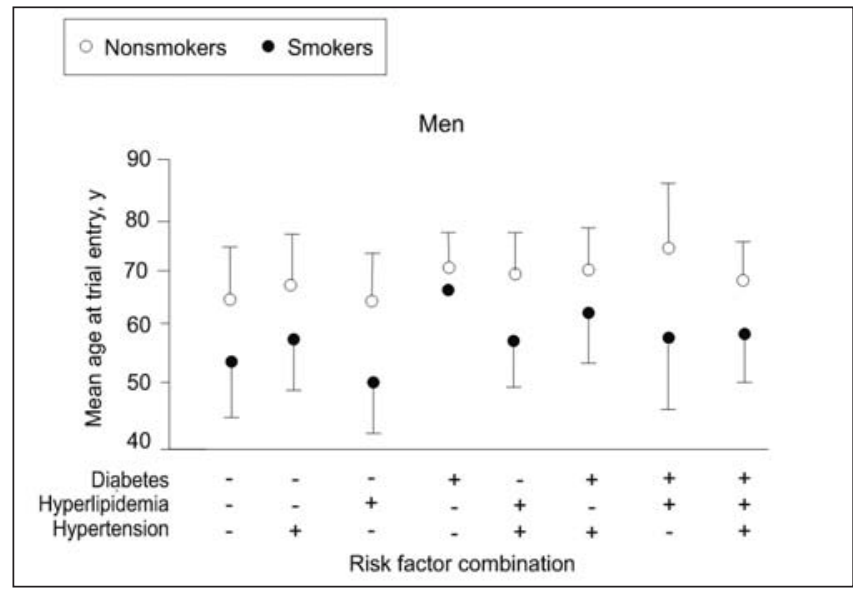

Fig. 2b. Relationship between conventional risk factor combinations and age at heart event stratified by smoking status in men.

For every risk factor combinantion, smoking reduces the age at heart event on average by 10.0 years in men and 12.4 years in women $(p<0.001$ for all smokers vs. non-smokers, except of +-- and ++- in both sexes because of small sample size). The error bars represent the standard deviations.

\section{DISCUSSION}

Most of the studies devoted to the prevalence of cardiovascular risk factors among patients with ACS have been conducted on the patients from North America, Western European countries or other countries outside Europe. Data from the region of Central and Eastern Europe are scarce. This is the first comprehensive study estimating the prevalence of conventional risk factors in patients with ACS in Slovakia.

\section{Main Findings}

The analysis of the collected data showed a considerably high prevalence of major risk factors in patients with ACS in our population. Nearly all men and women in our patient sample had at least one risk factor (hypertension, hyperlipidemia, diabetes or smoking) and over half of the patients had at least two risk factors. The higher prevalence of risk factors, except for smoking, was seen more frequently in women than in men, in older patients than in younger patients, and in rural areas than in urban areas. In both men and women, current cigarette smoking reduces by about one decade the age at which the heart-related event occurs.

Hence our results do not support the hypothesis mentioned above that more than half of the patients with coronary artery disease lacked any of the 4 conventional risk factors. In our patient sample, only $4 \%$ of men and $5 \%$ of women were free of any major risk factor, a finding consistent with some studies $(13,14)$, but not with others which have reported $10 \%$ to $20 \%$ of patients with myocardial infarction but no risk factor $(11,15)$. Clearly, the high prevalence of major risk factors identified in our study results from an insufficient level of primary prevention for cardiovascular disease in the general population.

\section{Age, Gender and Geographic Variation}

Overall, the prevalence of conventional risk factors in patients with ACS is related to age and gender. In addition, a significant racial and inter-country variation has been demonstrated. For example, the prevalence of diabetes mellitus in similarly aged men with myocardial infarction varied between $12 \%$ in eastcentral Canada and $40 \%$ in Jordan $(16,13)$. In women, the variation was even greater, ranging from $26 \%$ in Israel to $64 \%$ in neighbouring Jordan $(17,13)$. Similar variations between and within populations for ACS have been reported for conditions of elevated blood pressure, elevated cholesterol levels and smoking habits $(14,18,19)$.

Women are clearly older than men at the time of hospitalization for myocardial infarction $(11,13)$. In our study, the prevalence of conventional risk factors (except for cigarette smoking) adjusted to age was higher in women than in men. For example, a bulk of reports comparing men and women who had survived a myocardial infarction identified a higher proportion of diabetic women than of diabetic men $(11,13,20)$. In contrast, the only risk factor with a lower prevalence in women compared to men was cigarette smoking. However, young women are now smoking as much as young men; this increasing trend in the smoking habits of young women in Slovakia and in other economically transient countries has been noted over the last 15 years (21).

The appearance of ACS in young patients does not occur frequently. The proportion of patients with premature ACS $(<45$ years of age) was only $3.8 \%$ in the current study while in Israel, Spain and the USA it reached $10 \%(17,22,23)$. Earlier studies have demonstrated a greater familial influence on the development of ACS in young patients, compared to older patients, that is mediated by hypertension and familial hyperlipidemia (15). Several studies have also shown a substantial difference in major risk factors among younger and older patients with ACS (11, 15, 23).

Although family history was not considered in this study, our findings highlight the harmful impact of hypertension and cigarette smoking in young women and of cigarette smoking in young men on the incidence of cardiovascular disease. Overall, a history of hyperlipidemia and diabetes was seen less often in young than in elderly patients $(11,15)$. In contrast, the prevalence of smoking was five times higher among patients younger than 45 years of age compared to those over 65 years of age (68.9\% 
vs. $13.5 \%, \mathrm{p}<0.001$ ), a finding consistent with age-related differences observed in other studies $(11,24)$. The high prevalence of smoking among teenagers and young adults point to the urgent need for health intervention to reduce this habit.

Our findings also suggest that women are protected against the development of ACS until the menopause (M/F ratio 4.3 in patients <55 years of age). However, gender differences in mortality and morbidity become attenuated with increasing age (25). In summary statistics, only $8 \%$ of young patients were free from any risk factor in this study, a finding consistent with data observed in other studies $(11,15,24)$.

\section{Hypertension}

The most common risk factor in our patients with ACS was arterial hypertension, occuring in $85 \%$ of cases. The INTERHEART case-control study has estimated that $25 \%$ of heart-related cases in Central and Eastern European countries are due to a history of elevated blood pressure (26). In previous studies, the prevalence of hypertension in men and women with myocardial infarction ranges from $27 \%$ to $63 \%$, much less than in our patient sample $(13,19)$. To the best of our knowledge, the prevalence of hypertension in the current study is one of the highest in medical literature and can be partly explained by the relatively high prevalence of obesity, in women $38.2 \%$ and in men $26.6 \%$ (results not shown). Another possible reason for the high prevalence of hypertension is the higher intake of salt $(\mathrm{NaCl})$ in Slovakia, especially in men (>8 g of salt a day) (27).

Our finding that a history of hypertension is less frequent in patients with STEMI than in those with other ACS diagnoses is consistent with other observations $(11,28)$. The reason for this difference is not yet clear.

\section{Smoking}

Based on our own findings and the findings of the extensive Euro heart survey of ACS performed in 25 countries in Europe and the Mediterranen basin, cigarette smoking is the most serious risk factor for ACS, particularly in patients with STEMI (29). In this study, the incidence of current smoking for every risk factor combination reduced the age at trial entry by about ten years in both genders. In previous studies, a history of cigarette smoking is always higher in men than in women and in younger patients than in older patients with ACS, ranging from $11 \%$ to $77 \%$ (13, 23). The mean prevalence of smoking determined in our patients, however, was lower (27.6\%, range 4.1-71.4\%), possibly because of a larger number of patients in older age groups. In general, the lower prevalence of smoking in older patients with ACS as well as in the general population results from the changes in social, economic and cultural behaviour, for example the loss of social contacts, the worsening of chronic diseases, physical inactivity, low income, and lower alcohol consumption in this age group (30).

\section{Diabetes and Hyperlipidemia}

Diabetes and hyperlipidemia are traditionally considered important metabolic risk factors for cardiovascular disease. Diabetes not only substantially increases the risk of cardiovascular disease but also magnifies the impact of other cardiovascular risk factors such as elevated cholesterol levels, elevated blood pressure, smoking and obesity (31). The prevalence of diabetes in Slovakia is high ( $>6 \%$ of the population) and has increased rapidly over the last ten years (21). Among patients with ACS, previous reports have shown that the frequency of diabetes varies from $17 \%$ to $64 \%$, affecting predominatly middle-aged and older patients $(13,32)$. The gender-specific difference in the prevalence of diabetes in women and men observed in the current study (43.9\% vs. $26.6 \%$, $\mathrm{p}<0.001)$ is consistent with other studies $(11,13)$.

Lipid abnormalities are often associated with diabetes, particularly in those with type 2 diabetes. The lipid profile in these patients is characterized by hypertriglyceridemia and reduced HDL cholesterol levels (33). In general, LDL cholesterol and total cholesterol levels in type 2 diabetes are usually not significantly different from those of the non-diabetic population but may have an increased atherogenicity via higher concentrations of small, dense LDL particles (34). The comorbidity of diabetes and dyslipidemia often results from some environmental factors such as obesity and an unhealthy lifestyle (35).

\section{Urban-Rural Differences}

Currently, 30\% of Slovaks live in entirely rural areas and another $15 \%$ of the population live in settlements of up to only 5,000 inhabitants (12). Slovakia has been overwhelmed by great socioeconomic changes during the last 25 years, with a large migration flow of economically active populations from rural to urban regions. Our findings suggest that people who now live in rural and smaller urban areas are at a higher risk for ACS than those who live in larger agglomerations. Similarly, the prevalence rates of major risk factors, except for smoking, are significantly higher in patients with ACS in rural than in urban regions. This finding is consistent with some studies $(36,37)$ but not with others reporting a higher frequency of most cardiovascular risk factors in large cities $(38,39)$. The higher prevalence of heart events and major risk factors in a rural population in the present study can be explained by a greater proportion of older inhabitants who obviously have a low educational level, low income, unhealthy lifestyle, and less accessible medical care than their urban counterparts $(30,40)$.

\section{Survey Limitations}

The are several limitations to our survey. The ACS patients included in the study may not be representative of all patients with ACS, because patients who died before arrival to hospital were not included in this survey. A higher prevalence of major risk factors has been more often reported in patients with fatal myocardial infarctions than in those with non-fatal heart-related events (14).

Because blood pressure, glucose and lipid serum levels tend to change in patients with ACS, diagnosis for hypertension, diabetes mellitus and hyperlipidemia was often based on history. Therefore, the prevalence rates of these risk factors may be underestimated.

In addition, we did not have information on previous myocardial infarctions, history of angina pectoris or family history of premature cardiovascular disease. In particular, patients with a previous history of heart-related events could have modified their lifestyles to eliminate their risk profile. 


\section{CONCLUSIONS}

The present study is a case-retrospective survey of patients with ACS, utilizing uniform diagnostic and registration methods, and utilizing the criteria for identification of conventional risk factors for cardiovascular disease. All major risk factors for cardiovascular disease were present among patients with ACS. The cardiovascular risk profile is different for men and women, for younger and older patients, and for rural and urban populations. Hence our data suggest that risk factor modification should be targeted to specific groups of patients for optimal reduction of the risk of ACS. Further research should be aimed at estimating the effectiveness of such intervention strategies.

\section{Conflict of Interests}

None declared

\section{Acknowledgement}

The authors wish to thank all physicians who collaborated in the formation of the SLOVAKS registry in the fields of methodology, organization and clinical practice.

\section{REFERENCES}

1. Health Statistics Yearbook of the Slovak Republic 2012. Bratislava (SK): National Health Information Centre; 2014.

2. Nichols M, Townsend N, Scarborough P, Rayner M. Trends in agespecific coronary heart disease mortality in the European Union over three decades: 1980-2009. Eur Heart J. 2013 Oct;34(39):3017-27.

3. Fuster V, Kelly BB. Epidemiology of cardiovascular disease. In: Fuster V, Kelly BB, editors. Promoting cardiovascular health in the developing world: a critical challenge to achieve global health. Washington (DC): National Academic Press; 2010. p. 49-124.

4. Avdičová M, Hrubá F. Genetic and exogenous risk factors of coronary artery disease in Slovak population - study results within CINDI Programe. Interná Med. 2002;2(8):467-72. (In Slovak.)

5. Cífková R, Škodová Z, Bruthans J, Adámková V, Jozífová M, Galovcová $\mathrm{M}$, et al. Longitudinal trends in major cardiovascular risk factors in the Czech population between 1985 and 2007/8. Czech MONICA and Czech post-MONICA. Atherosclerosis. 2010 Aug;211(2):676-81.

6. Studenčan M, Baráková A, Hlava A, Murín J, Kamenský G. SLOVak register of Acute Coronary Syndromes (SLOVAKS) - analysis of data from 2007. Cardiol. 2008;17(5):177-88. (In Slovak.)

7. Heller RF, Chinn S, Pedoe HD, Rose G. How well can we predict coronary heart disease? Findings in the United Kingdom Heart Disease Prevention Project. Br Med J (Clin Res Ed). 1984 May 12;288(6428):1409-11.

8. Van de Werf F, Bax J, Betriu A, Blomstrom-Lundqvist C, Crea F, Falk V, et al; ESC Committee for Practice Guidelines (CPG). Management of acute myocardial infarction in patients presenting with persistent ST-segment elevation: the Task Force on the Management of ST-Segment Elevation Acute Myocardial Infarction of the European Society of Cardiology. Eur Heart J. 2008 Dec;29(23):2909-45.

9. Task Force for Diagnosis and Treatment of Non-ST-Segment Elevation Acute Coronary Syndromes of European Society of Cardiology, Bassand JP, Hamm CW, Ardissino D, Boersma E, Budaj A, Fernández-Avilés F, et al. Guidelines for the diagnosis and treatment of non-ST-segment elevation acute coronary syndromes. Eur Heart J. 2007 Jul;28(13):1598660 .

10. Hamm CW, Braunwald E. A classification of unstable angina revisited. Circulation. 2000 Jul 4;102(1):118-22.

11. Khot UN, Khot MB, Bajzer CT, Sapp SK, Ohman EM, Brener SJ, et al. Prevalence of conventional risk factors in patients with coronary heart disease. JAMA. 2003 Aug 20;290(7):898-904.

12. Population and housing census 2011. Bratislava (SK): Statistical office of the Slovak Republic; 2012.
13. Hammoudeh AJ, Al-Tarawneh H, Elharassis A, Haddad J, Mahadeen Z, Badran N, et al. Prevalence of conventional risk factors in Jordanians with coronary heart disease. The Jordan Hyperlipidemia and Related targets Study (JoHARTS). Int J Cardiol. 2006 Jun 16;110(2):179-83.

14. Greenland P, Knoll MD, Stamler J, Neaton JD, Dyer AR, Garside DB, et al. Major risk factors as antecedents of fatal and nonfatal coronary heart disease events. JAMA. 2003 Aug 20;290(7):891-7.

15. Hoit BD, Gilpin EA, Henning H, Maisel AA, Dittrich H, Carlisle J, et al. Myocardial infarction in young patients: an analysis by age subsets. Circulation. Circulation. 1986 Oct;74(4):712-21.

16. Labos C, Wang RHL, Pilote L, Bogaty P, Brophy JM, Engert JC, et al. Traditional risk factors and a Genetic Risk Score are associated with age of first acute coronary syndrome. Heart. 2014 Oct;100(20):1620-4.

17. Benderly M, Behar S, Reicher-Reiss H, Boyko V, Goldbourt U. Longterm prognosis of women after myocardial infarction. SPRINT Study Group. Secondary Prevention Reinfarction Israeli Nifedipine Trial. Am J Epidemiol. 1997 Jul 15;146(2):153-60.

18. Lowry PJ, Lamb P, Watson RD, Ellis KE, Singh SP, Littler WA, et al. Influence of racial origin on admission rates of patients with suspected myocardial infarction in Birmingham. Br Heart J. 1991 Jul;66(1):29-35.

19. Jamil G, Jamil M, Alkhazraji H, Haque A, Chedid F, Balasubramanian M, et al. Risk factor assessment of young patients with acute myocardial infarction. Am J Cardiovasc Dis. 2013 Aug 16;3(3):170-4.

20. Becker A, Bos G, de Vegt F, Kostense PJ, Dekker JM, Nijpels G, et al. Cardiovascular events in type 2 diabetes: comparison with nondiabetic individuals without and with prior cardiovascular disease: 10-year followup of the Hoorn Study. Eur Heart J. 2003 Aug;24(15):1406-13.

21. Nichols M, Townsend N, Scarborough P, Rayner M, Leal J, LuengoFernandez R, et al. European cardiovascular disease statistics 2012 edition. Brussels: European Heart Network AISBL; 2012.

22. Pineda J, Marin F, Roldán V, Valencia J, Marco P, Sogorb F. Premature myocardial infarction: clinical profile and angiographic findings. Int J Cardiol. 2008 May 7;126(1):127-9.

23. Doughty M, Mehta R, Bruckman D, Das S, Karavite D, Tsai T, et al. Acute myocardial infarction in the young - the University of Michigan experience. Am Heart J. 2002 Jan;143(1):56-62.

24. Morillas PJ, Cabadés A, Bertomeu V, Echanove I, Colomina F, Cebrián $\mathrm{J}$, et al; Investigadores del PRIMVAC. Acute myocardial infarction in patients under 45 years. Rev Esp Cardiol. 2002 Nov;55(11):1124-31. (In Spanish.)

25. de Torbal A, Boersma E, Kors JA, van Herpen G, Deckers JW, van der Kuip DA, et al. Incidence of recognized and unrecognized myocardial infarction in men and women aged 55 and older: the Rotterdam Study. Eur Heart J. 2006 Mar;27(6):729-36.

26. Yusuf S, Hawken S, Ounpuu S, Dans T, Avezum A, Lanas F, et al; INTERHEART Study Investigators. Effect of potentially modifiable risk factors associated with myocardial infarction in 52 countries (the INTERHEART study): case-control study. Lancet. 2004 Sep 11-17;364(9438):937-52.

27. Chudíková K, Havelková B, Michalovičová M, Rovný I. Evaluation of the nutritional condition of the population of the Slovak Republic in relation to cardivascular risk. Cardiol. 2005;14(1):27-36. (In Slovak.)

28. Rogers WJ, Frederick PD, Stoehr E, Canto JG, Ornato JP, Gibson CM, et al. Trends in presenting characteristics and hospital mortality among patients with ST elevation and non-ST elevation myocardial infarction in the National Registry of Myocardial Infarction from 1990 to 2006. Am Heart J. 2008 Dec;156(6):1026-34.

29. Rosengren A, Wallentin L, Simoons M, Gitt AK, Behar S, Battler A, et al. Cardiovascular risk factors and clinical presentation in acute coronary syndromes. Heart. 2005 Sep;91(9):1141-7.

30. Zavazalova H, Nemeth F, Zikmunova K, Zaremba V, Rais V. Some indicators of quality of life in senior age in two regions: international comparative study - the Czech Republic and the Slovak Republic. Bratisl Lek Listy. 2007;108(4-5):212-7.

31. Sowers JR, Epstein M, Frohlich ED. Diabetes, hypertension, and cardiovascular disease. An update. Hypertension. 2001 Apr;37(4):1053-9.

32. Carević V, Kuzmanić M, Rumboldt M, Rumboldt Z; INTERHEART Investigators. Predictive impact of coronary risk factors in Southern Croatia: a case control study. Coll Antropol. 2010 Dec;34(4):1363-8.

33. Kreutz AJ. Lipoprotein abnormalities and their consequences for patients with Type 2 diabetes. Diabetes Obes Metab. 2003 Nov;5 Suppl 1:S19-27.

34. Hayashi T, Hirano T, Yamamoto T, Ilo Y, Adachi M. Intensive insulin therapy reduces small dense low-density lipoprotein particles in patients with type 2 diabetes mellitus: relationship to triglyceride-rich lipoprotein subspecies. Metabolism. 2006 Jul;55(7):879-84. 
35. Hu FB, Li TY, Colditz TA, Willett WC, Manson JE. Television watching and other sedentary behaviors in relation to risk of obesity and type 2 diabetes mellitus in women. JAMA. 2003 Apr 9;289(14):1785-91.

36. Lindroth M, Lundqvist R, Lilja M, Eliasson M. Cardiovascular risk factors differ between rural and urban Sweden: the 2009 Northern Sweden MONICA cohort. BMC Public Health. 2014 Aug 9;14:825.

37. Peach HG, Bath NE. Prevalence and sociodemographic determinants of cardiovascular risk in a rural area. Aust J Rural Health. 1999 Feb;7(1):237.

38. Garcia-Palmieri MR, Sorlie PD, Havlik RJ, Costas R Jr, Cruz-Vidal M. Urban-rural differences in 12 year coronary heart disease mortality: the Puerto Rico Heart Health Program. J Clin Epidemiol. 1988;41(3):285-92.
39. Chadha SL, Gopinath N, Shekhawat S. Urban-rural differences in the prevalence of coronary heart disease and its risk factors in Delhi. Bull World Health Organ. 1997;75(1):31-8.

40. Škodová Z, Nagyová I, Rosenberger J, van Dijk JP, Middel B, Vargová $\mathrm{H}$, et al. Vital exhaustion in coronary heart disease: the impact of socioeconomic status. Eur J Cardiovasc Prev Rehabil. 2008 Oct;15(5):572-6.

Received March 18, 2015 Accepted in revised form July 7, 2016

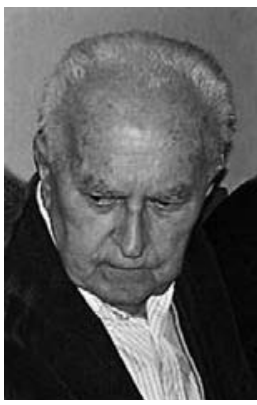

Eminent Czech Virologist Dimitrij Slonim Passes Away

The eminent Czech virologist, Assoc. Prof. Dimitrij Slonim, MD, has died at the age of 92 (August 4, 1925 - January 3, 2017) after a short illness. Dimitrij Slonim devoted his whole professional life to the study of virology and immunology and was a respected expert both in the Czech Republic and abroad.

His studies at the Medical Faculty of Charles University began in 1945, followed by graduation in 1951. From 1956 to 1986 he held a number of leading positions at the Institute of Vaccines and Sera (IVS) as well as a scholarship at Connaught Research Labs in Toronto in 1969-1970.

During his 30 years of research at IVS he formed and led a team responsible for the development and production of 7 antiviral vaccines and 27 diagnostic preparations, whilst publishing cutting-edge work in the field of virology.

This research led to the manufacture of vaccines in the former Czechoslovakia, such as inactive and live active poliomyelitis vaccines, live smallpox vaccine, inactive rabies vaccine and live vaccines, single and combined, against measles and mumps.

Professor Slonim's team was the first in the world to consistently create live oral polio vaccine for nationwide vaccination programmes for children, leading to the eradication of this disease in this country. His groundbreaking experience and research activities led him to assume important roles in the formulation of WHO and national policies for the manufacture of vaccines, and the WHO smallpox eradication programme.

Professor Slonim leaves behind an impressive legacy of publications and is remembered not only as an outstanding specialist, but also for his kindness, tolerance and encompassing interest in the arts and culture, and the Blatensko region where he was born.

Sylvie Kvášová, Pavla Křížová, Jitka Částková, Vladimír Polanecký

A shortened version republished with permission of the Editorial Board of Epidemiologie, mikrobiologie a imunologie.

Photo by Dr. Švec: Dimitrij Slonim at meeting in 2013 